\title{
A memória em trânsito: uma leitura da Via Sacra enquanto construção coletiva
}

\author{
Memory in transit: an interpretation of the Via Crucis as a collective construction \\ Renata Cristina de Souza Nascimento \\ (iD) https://orcid.org/0000-0002-9584-362X \\ Universidade Federal de Goiás
}

\begin{abstract}
Resumo: Tendo por guia a obra de Maurice Halbwachs "La topographie légendaire des évangiles en Terre Sainte", pretendo discutir a constituição dos lugares-memória do cristianismo, dando destaque à Via Sacra. Revisitando estes lugares o passado se reatualiza na memória coletiva, fortalecendo a religião cristã. A tradição presente nestes espaços fundantes é a base do cenário histórico - religioso, que foi e é constantemente revivido em diversas regiões. A via- crucis é exemplo claro desta rememoração intensa, estando presente também no imaginário religioso $e$ artístico brasileiro. As representações artísticas da Via Sacra contribuem para o fortalecimento do patrimônio simbólico, e são elementos fundamentais na reinvenção de uma toponímia sagrada. $O$ objetivo deste artigo é apresentar alguns elementos desta tradição em consonância com o conceito de memória coletiva. Na tradição cristã lugares, imagens e objetos serviram como elementos de "reevocação" de um passado memorável, que se desejava perpetuar.
\end{abstract}

Palavras-chave: Terra Santa. Via Dolorosa. Memória Coletiva.

Abstract: Guided by Maurice Halbwachs's work "La topographie légendaire des évangiles en Terre Sainte", I intend to discuss the constitution of the memory places of Christianity, highlighting the Via Sacra. Revisiting these places, the past is renewed in the collective memory, strengthening the Christian religion. The tradition present in these founding spaces is based on the historical - religious scenario, which was and is constantly revived in various regions. Via crucis is a clear example of this intense remembrance, being also present in the Brazilian religious and artistic imagination. The artistic representations of the Via Sacra contribute to the strengthening of the symbolic heritage, and are fundamental elements in the reinvention of a sacred toponym. The purpose of this paper is to present some elements of this tradition in line with the concept of collective memory. In christian tradition, places, images, and objects served as elements of a "recall" of a memorable past that one wished to perpetuate.

Keywords: Holy Land. Via Dolorosa. Collective Memory.

A experiência do sagrado é permeada por uma série de rituais e símbolos, que fortalecem sua existência no tempo. Conforme Jean-Claude Schmitt (2014, p.35) a religião não consiste na conviç̧ão privada de um crente: é um imaginário social que contribui, pela representação (mental, ritual, imagética) de um lugar que podemos nomear o divino, para ordenar e legitimar as relações dos homens entre si. Para que um fenômeno religioso possa ser consolidado precisa de elementos fundantes, distintos, e que possuam status especial, divino. Neste processo é necessária uma associação entre espaço e memória. Nestes lugares considerados especiais estão presentes elementos que validam um passado épico. As pedras, os monumentos e até mesmo a Esta obra está licenciada sob uma Creative Commons - Atribuição 4.0 Internacional 
terra de Jerusalém são consideradas sagradas, e auxiliam na construção de recordações individuais e coletivas.

As narrativas bíblicas e também dos "pais da Igreja" contribuíram para a distinção deste espaço como santificado. A Terra Santa (como um todo) reúne uma topografia, um mapa, no qual considera-se que o próprio Deus encarnado esteve presente. Esta espécie de inventário geográfico auxiliou e fortaleceu os laços entre este mundo e o além. Fator comum e bastante perceptível são as disputas por seu patrimônio sacro. No cristianismo observa-se a ideia de um eterno retorno à Terra Santa, seja através de imagens e/ou palavras. Esta sacra representação é guiada pelos Evangelhos, que oferecem uma descrição dos lugares em que Cristo esteve, e cumpriu sua missão. Nosso objetivo é discutir a construção do imaginário da Via Dolorosa, inserindo-o no conceito de memória coletiva. Para tanto dividimos o artigo em três partes: Maurice Halbwachs e a Memória Coletiva Cristã; 2- Via Dolorosa: Dimensão Simbólica; 3Representações Artísticas: O Sacrifício na Cruz Como Memória Visual.

\section{Maurice Halbwachs e a Memória Coletiva Cristã}

No âmbito acadêmico brasileiro os estudos sobre o conceito de memória se intensificaram a partir da década de 1980, e se consolidaram paulatinamente. O tema memória tornou-se objeto de amplo debate. Entre estas reflexões sobre memória escolhemos como eixo de análise as discussões apresentadas pelo teórico francês Maurice Halbawachs (1877- 1945), por se aproximarem também da temática da memória coletiva cristã. Em 1925 Halbwachs publicou Les Cadres Sociaux de la Mémoire; em 1941 La topographie légendaire des évangiles en Terre Sainte: étude de mémoire collective, como produto de duas viagens de estudo realizadas a Palestina ${ }^{1}$; Seus textos sobre memória escritos entre 1925-1944 foram editados em 1950, em obra póstuma, sob o título La Mémoire Collective, traduzida também ao português. Nestas obras percebe-se a influência da noção de memória social, herdada de Émile Durkheim (2003). Em seus escritos o autor parte do princípio de que os contextos sociais reais servem de baliza ao que chamamos memória. "Para evocar seu próprio passado, em geral, a pessoa precisa recorrer às lembranças de outras e se transporta a pontos de referência que existem fora de si, determinados pela sociedade" (HALBAWACHS, 2003, p. 72). Esta relação também se estabelece entre memória coletiva e memória histórica, em que um grupo se apodera de uma representação coletiva comum. No caso do cristianismo, que é o que nos interessa aqui, houve uma apropriação destas lembranças, inseridas no espaço da Terra Santa. Esta mitificação de uma região fortaleceu a identidade e a pretensão de atemporalidade histórica. Cristo e seus discípulos, fundadores das primeiras comunidades, são modelos essenciais na construção de uma história que se considera sublime. O sentido de pertencimento do povo cristão à história concretiza-se nas pedras e espaços, marcados pela presença física do Messias na terra.

Vemos, portanto, em que medida a descoberta - ou seja, a revelação - do espaço sagrado tem um valor existencial para o homem religioso; porque nada pode começar, nada se pode fazer sem uma orientação prévia - e toda orientação implica a aquisição de um ponto fixo. É por esta razão que o homem religioso sempre se esforçou por estabelecer-se no "Centro do Mundo". (ELIADE, M. 1992, p. 17)

\footnotetext{
${ }^{1}$ O autor visitou a Terra Santa em 1927, e também em 1939.
} 
O simbolismo de um espaço sagrado o torna qualitativamente diferente dos demais. Por este motivo Jerusalém é considerada a cidade mais santa da história cristã e nos mapas medievais era o ponto paradoxal, o centro do mundo. Estes locais espiritualmente privilegiados tornam-se cenários iniciais dos ritos aí estabelecidos, que se deslocariam também para outros espaços da cristandade. O conjunto de recordações presentes na Terra Santa foi coletivamente instituído e compartilhado, independente da exatidão histórica dos locais. O que importa é a construção desta arqueologia sagrada, amparada nos Evangelhos. O interesse de Maurice Halbawachs pela memória coletiva o fez trilhar os caminhos da Palestina. Destas experiências concretas produziu La topographie légendaire des évangiles en Terre Sainte: étude de mémoire collective, como já mencionado. A obra divide-se em 8 capítulos: I - Le Pèlerin de Bordeaux, II Bethlèem, III - Le Cénacle et le tombeau de David, IV - Le Prétoire de Pilate, V- La Voie Douloureuse, VI - Le Mont des Oliviers, VII - Nazareth, VIII - Le Lac de Tibériade. Já na introdução o autor afirma: "Le Voyage em terre sainte peut être fait dans des dispositions d'esprit assez diferentes. Pour beaucoup, c'est un pèlerinage. Ils veulent voir les lieus où se sont passes les événements rapports par les Évangiles [...]" (HALBAWACHS, 1941, p. 1).

O Itinerarium Burdigalense (ou narrativa do peregrino de Bordeaux) é considerado o relato cristão mais antigo aos lugares santos, e foi realizado no século IV. O interesse do autor por este relato se deu por considerá-lo um formador da memória coletiva sobre os caminhos da Terra Santa, sobre como esta experiência espiritual forneceu um modelo peregrinatório. Os lugares de memória deram ao cristianismo uma concretude, uma atualização permanente do passado. Estes pontos de referência se constituem em símbolos de fé, distribuídos no solo desta região. A memória individual torna-se coletiva na medida em que é compartilhada por um grupo. Este por sua vez molda a memória individual submetendo-a aos interesses deste mesmo grupo. Os eventos e sua posterior rememoração são de extrema importância para a doutrina cristã, pois compõem seu centro e fundam a comemoração da vida de Jesus que dá o tom da religião cristã (CORDEIRO, 2015, p. 122). Os valores compartilhados teriam longa existência quando institucionalizados, ritualizados, pois conforme Halbawachs (1941); "a memória dos grupos retém muito bem as verdades, as noções, as ideias, as proposições gerais, e a memória do grupo religioso conserva a lembrança das verdades dogmáticas que foram reveladas por trás dele, ou que as sucessivas gerações dos fiéis e dos clérigos fixaram ou reformularam"2. Esta construção coletiva do passado seria partilhada através de eventos, textos e locais, como se deu na memória cristã. Entre estes elementos de rememoração daremos destaque à ritualização da Via Dolorosa.

\section{Via Dolorosa: Dimensão Simbólica}

As formas específicas de devoção e piedade popular foram sendo construídas e reconstruídas, à medida que a religião cristã se fortalecia dentro das fronteiras do mundo romano. Neste contexto, os locais ligados a um episódio do Antigo ou do Novo Testamento tiveram uma posição à parte: tradições judaicas, memórias cristãs e lendas locais contribuíram para um inventário em perpétuo crescimento, num movimento sem precedentes de apropriação do espaço (PERRIN, 2008, p. 88). O desenvolvimento de práticas simbólicas foi importante para dar visibilidade e dramaticidade à nova fé.

\footnotetext{
2 Tradução oferecida por CORDEIRO, Veridiana Domingos, 2015.
} 
A passagem do cristianismo de seita criminosa e perseguida a uma religião de Estado, necessitava de uma afirmação identificável na cena urbana e na vida cotidiana. No processo de invenção e reinvenção de recordações insere-se a teatralização da Via Sacra. Nos primeiros tempos a Igreja não havia instituído o percurso total da Via-Crucis em Jerusalém. As peregrinações na Antiguidade Tardia foram acentuadas a partir do século IV, e os primeiros viajantes à Terra Santa eram em geral membros do clero ou cristãos piedosos que pelo contato tangível almejavam um crescimento espiritual. Dentre este grupo destacavam-se várias mulheres da aristocracia como Helena (esteve na Palestina em 326), Melânia - a - Velha (373) e Egéria/ Etéria, que empreendeu seu itinerário provavelmente entre 381-384. Esta viajante - peregrina vivenciou a Semana Santa em Jerusalém, e deixou um registro detalhado das festividades e dos rituais existentes ali. Sobre o Domingo de Ramos apresenta a seguinte narrativa:

No outro dia, pois, isto é, no domingo que dá entrada na semana pascal, que aqui designam por a grande semana celebrada desde o cantar dos galos o que é de costume ser feito na Anástase e na Cruz até de manhã, no domingo, pois, de manhã, vai-se como de costume à igreja maior que é designada Martyrium. A razão por que é designada por Martyrium é porque está no Gólgota, isto é, atrás da Cruz, onde o Senhor sofreu, e por isso tem o nome Martyrium. ${ }^{4}$

Figura 1: 14 Estações Atuais da Via Dolorosa ${ }^{5}$

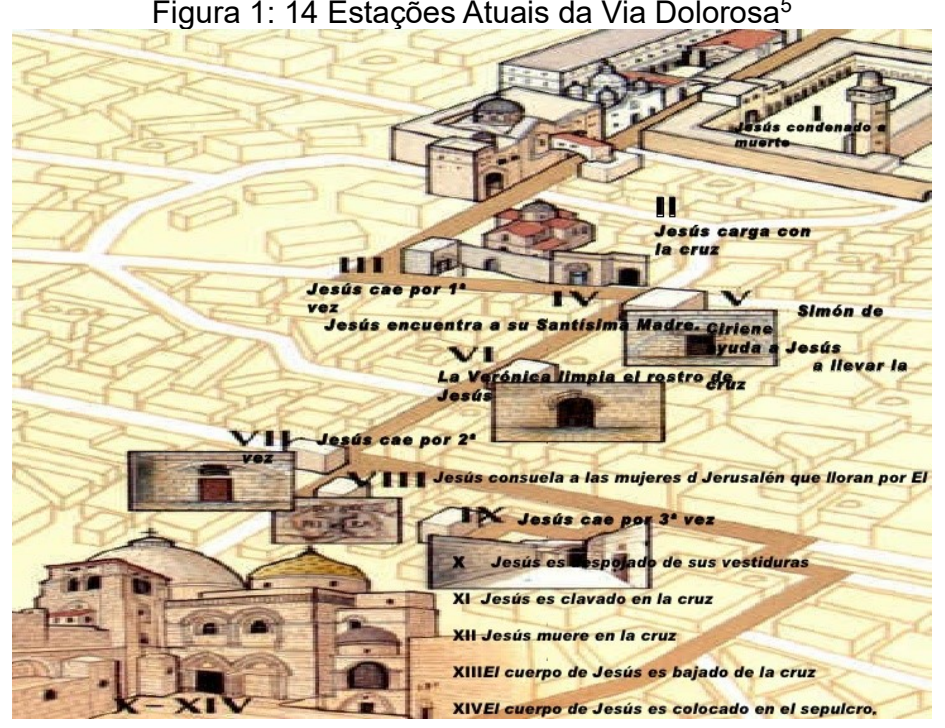

O Martyrium era composto de uma parte suntuosa, na qual encontrava-se a cripta da Invenção da Santa Cruz. Participar dos atos litúrgicos era uma oportunidade de imitar Cristo, seguindo seus passos durante as procissões, realizadas pelas ruas da cidade santa. Esta experiência permitia aos fiéis entrar no reino do sagrado, vivenciando a presença de Deus. A imitação de Cristo, em sua forma de vida, paixão e morte, tornouse mais intensa a partir do século XIII, fomentando uma forte sensibilidade ao redor dos sofrimentos do Salvador. A custódia dos lugares sagrados foi confiada à Ordem Franciscana. Por influência dos freis franciscanos há um fomento da devoção à Paixão de Cristo. Os estigmas de São Francisco fornecem o exemplo de uma verdadeira e

\footnotetext{
${ }^{3}$ Viúva de um prefeito de Roma.

${ }^{4}$ In: Egéria. Viagem do Ocidente à Terra Santa, no Séc. IV (Itinerarium ad loca sancta). Edição de Alexandra B. Mariano e Aires do Nascimento. Lisboa: Colibri, 2009 (2 $2^{\mathrm{a}}$ tiragem). p 205.

${ }^{5}$ Fonte: https://avivenciaravida.blogspot.com/2018/03/a-via-dolorosa.html
} 
concreta participação nos sofrimentos de Jesus. Conforme S. Boaventura na Legenda Maior: "Francisco, transformado em homem novo, resplandeceu por um prodígio também novo e inaudito [...] ao ser divinamente condecorado com os sagrados estigmas, e dessa forma se assemelhar já em seu corpo mortal, ao próprio corpo do Senhor crucificado"6. E mais adiante: "Dessa forma, em virtude de repetidas aparições da cruz do Senhor, num impulso e êxtase de amor, começava a transformar-se em imagem viva do Crucificado, tanto nos pensamentos e afectos do coração como até em atitudes externas"7. Esta identificação da Ordem com a devoção à Santa Cruz contribuiu para que os episódios da Paixão fossem revividos passo a passo, no exercício espiritual da Via Dolorosa. Nasce então uma meditação que dividiu o curso das dores sofridas durante a crucificação em episódios; a condenação, flagelação, o caminho até o calvário, etc. Esta assimilação à ideia de Via Sacra foi gradativa.

Os Evangelhos oferecem pistas sobre o caminho da Paixão, do Palácio de Pilatos até sua crucificação no Gólgota. Conforme Mateus 27: 2: "Assim, amarrando-o, levaram-no e entregaram-no a Pilatos, o governador". Ao trajeto apresentado nos Evangelhos acrescenta-se a tradição existente também nos Livros Apócrifos. Até o final do século XV o caminho até o Calvário foi se convertendo em uma peregrinação ritualizada, em uma forma de penitência, para que o cristão pudesse presenciar, participar, sentir a mesma dor do próprio Cristo. No início eram apenas sete estações, sendo no fim da era moderna (século XVII) ampliada para 14 estações $^{8}$. As últimas quatro encontram-se atualmente na Igreja do Santo Sepulcro em Jerusalém. O marcante simbolismo da Via Dolorosa converteu-se em um percurso sagrado.

Figura 2: Placa do Percurso em Jerusalém ${ }^{9}$

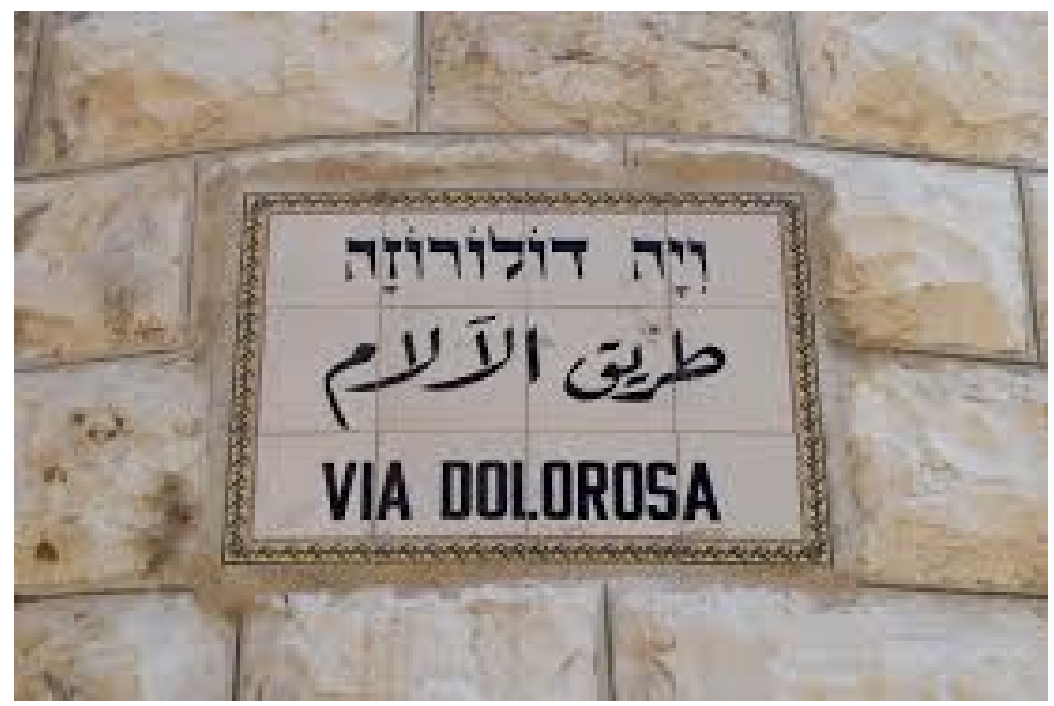

Ao fazer este trajeto Halbwachs reviveu a tradição cristã, relatando-a no capítulo $\checkmark$ de seu livro La topographie légendaire des évangiles en Terre Sainte: "[...] elles

\footnotetext{
${ }^{6}$ Citado em FONTES FRANCISCANAS (I) SÃO FRANCISCO DE ASSIS. Escritos. Biografias. Documentos. Braga: Editorial Franciscana, 2005, p 696.

${ }^{7}$ Citado em FONTES FRANCISCANAS (I) SÃO FRANCISCO DE ASSIS. Escritos. Biografias. Documentos. Braga: Editorial Franciscana, 2005, p 697.

${ }^{8}$ São Leonardo de Porto Maurício (1676-1751) foi um dos principais idealizadores da Via Sacra no Coliseu (Roma).

${ }_{9}^{9}$ Fonte: https://www.arwtravels.com/blog/4-days-jerusalem-walking-via-dolorosa
} 
montrent à quel point la merveilleuse et sublime histoire de la Passion s'est gravée dans la mémoire des hommes" (1941, p. 102). A prática da Via Dolorosa, da forma que a conhecemos atualmente, atravessou um longo tempo de aperfeiçoamento, agregando posteriormente alguns episódios. Este caminho da cruz é essencial para a solidificação da memória cristã, pois garante a permanência viva de seu passado glorioso, épico e divino.

\begin{abstract}
Assim, não há memória coletiva que não aconteça em um contexto espacial. Ora, o espaço é uma realidade que dura: nossas impressões se sucedem umas às outras, nada permanece em nosso espírito e não compreenderíamos que seja possível retomar o passado se ele não estivesse conservado no ambiente material que nos circunda. É ao espaço, ao nosso espaço - o espaço que ocupamos, por onde passamos muitas vezes, a que sempre temos acesso e que, de qualquer maneira, nossa imaginação ou nosso pensamento a cada instante é capaz de reconstruir que devemos voltar nossa atenção, é nele que nosso pensamento tem de se fixar para que essa ou aquela categoria de lembranças apareça. (HALBWACHS, 2003, p. 170)
\end{abstract}

Apesar das diversas mudanças políticas e das vicissitudes sofridas ao longo dos séculos a Terra Santa jamais perdeu seu status e significado histórico. O Ocidente viveu, e ainda vive uma espécie de aventura arqueológica, pois em todas as regiões que professam o cristianismo há uma tentativa constante de identificação de seu território com Jerusalém. Em imagens e palavras a Terra Santa se faz presente. Neste âmbito de transferência da topografia espiritual da Palestina ampliou-se a popularidade visual da Via - Crucis. Atualmente o Magistério prescreve 14 estações, em alguns casos acrescentando uma décima quinta, que retrata a ascensão do filho de Deus aos céus.

\title{
Representações Artísticas: O Sacrifício na Cruz Como Memória Visual
}

Conforme as palavras do apóstolo Paulo em Gálatas (6:14); "Quanto a mim, não aconteça gloriar-me senão na cruz de nosso Senhor Jesus Cristo, por quem o mundo está crucificado para mim e eu para o mundo". O sofrimento de Cristo no Calvário foi o tema mais representado na arte Ocidental. A linguagem artística construiu sua própria narrativa, dando intensidade visual à dor vivida por Jesus, sacrificando-se para a salvação dos homens. O motivo religioso mais sublime, que a arte multiplica, é fundamental na solidificação da memória, um mergulho visual na teologia da cruz. Dentre este mosaico infinito de representações sacras, ligadas ao advento da crucificação, escolhemos algumas que dão visibilidade e solidez à memória coletiva sobre a Via Dolorosa. Imagens presentes em nossa memória, conforme Halbwachs, que se constituem em uma realidade palpável.

No fim da Idade Média ocorreu gradativamente uma ampla transposição imitativa dos Passos da Paixão na Europa, que será intensa nos séculos seguintes. Esta necessidade de perpetuação fortaleceu os "espaços de recordação", que expressam uma nostalgia, um desejo de peregrinar no solo sagrado da Palestina. Deste modo reproduções do venerável caminho doloroso dos últimos momentos de Cristo são delineados. Deste modo cada cidade, cada paróquia poderia realizar sua própria peregrinação à Jerusalém Destes mosaicos de representações espaciais do sagrado existem construções icônicas, de grande simbolismo e relevância artística, espalhadas ao redor do mundo. Em Portugal ainda no século XIV foi erguida uma ermida no Monte Espinho, em Braga, consagrada à Santa Cruz. Após o aumento da devoção e a necessidade de evangelização e catequização promovida pelo Concílio de Trento vários 
montes - sacros foram surgindo. No Bom Jesus do Monte (Braga), o caminho devocional foi traçado e uma suntuosa igreja construída (século XVIII) ${ }^{10}$. Este local reúne todos os componentes da Via Dolorosa, e também representa um esforço físico e espiritual, devido à sua dificuldade de acesso. $O$ caminho árduo do cristão nesta vida se converteu em um rito, em uma forma de penitência, em que cada um deve enfrentar sua própria via- crucis.

O Culto da Paixão (e em seguida da Santa Vera Cruz) teve início como prática autônoma, que depois foi institucionalizada, demonstrando a intensidade deste fenômeno religioso. Representações da Via Sacra decoram o interior dos santuários, e possuem grande valor artístico, histórico e litúrgico. O papa Bento XIV (1675-1740) incentivou sua inserção nas igrejas, e no século XIX a Via Dolorosa assumiu uma perspectiva mais narrativa. No Estado de Goiás (Brasil) duas importantes representações merecem destaque: $1^{\circ}$ - A Via-Sacra - 14 criações de Frei Nazareno Confaloni, que foram pintadas em 1965; $2^{\circ}$ - A Via Dolorosa de Trindade - Conjunto de obras de arte, em tamanho real feitas pelo artista plástico Elias Santos, na Cidade de Trindade (Goiás-Brasil) inauguradas em 2002. Estas imagens contribuem para o fortalecimento do patrimônio cultural goiano, e são elementos fundamentais na reinvenção de uma toponímia sagrada. As 14 estações em Trindade-GO se constituem em um dos principais pontos de peregrinação visitados pelos romeiros.

A cada parada, a que denominamos estações, a arte sacra tem dedicado grande atenção. Frei Nazareno Confaloni ${ }^{11}$, que chegou a Goiás em 1950 (vindo da Itália) dedicou parte de sua obra a representação da Via - Crucis. Conforme PX Silveira (2019), antes do conjunto completo Confaloni já havia pintado algumas cenas da Via - Sacra, principalmente o momento da crucificação. "Na verdade, o primeiro seu conjunto de pinturas de que temos notícia retratando a Via - Sacra foi feito por Confaloni no Brasil em 1953, na Igreja Santo Antônio, em Hidrolândia (Goiás) e que infelizmente, já não existe mais" (SILVEIRA, 2019, p. 9). Sua Via - Sacra completa ${ }^{12}$, constituída por 14 obras-primas foram inicialmente destinadas para decorar a capela de um convento dominicano em Fiesole (Itália), mas posteriormente foram trazidas para Goiás (1996). "É uma criação de forte conotação expressionista, porém construída com economia de elementos e colorida com moderação" (SILVEIRA, 2019). O simbolismo intrínseco a estas obras é uma forma de rememoração da tradição cristã, e nos revelam os caminhos de uma história das devoções. Cenas dramáticas da vida de Jesus, que encorajam o fiel a enfrentar sua caminhada terrena, identificando-se com Cristo e seus sofrimentos. Presença contínua de um passado sempre presente, reconectado através de encenações, imagens e textos.

\footnotetext{
10 No século XIX tornou-se um dos maiores centros de peregrinação em Portugal.

${ }^{11}$ Nasceu em 1917.

12 Atualmente estão na Paróquia Nossa Senhora Auxílio dos Cristãos (Goiânia-GO).
} 
Figura 3: Jesus carrega a cruz (Via Sacra de Frei Confaloni $)^{13}$

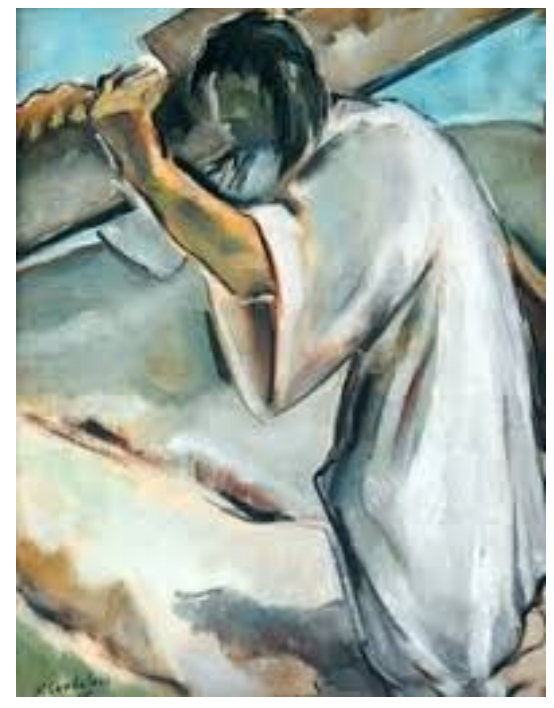

Figurações de uma memória identitária e celebrativa da doutrina cristã, estas imagens são certidões visuais revigorantes, que tem a função de fortalecimento da fé, de aproximação entre Deus e os homens. Elementos simbólicos que possuem grande significado, valor e sentido próprio.

\section{Considerações Finais}

A reevocação não é algo passivo, mas a recuperação de um conhecimento ou sensação anteriormente experimentada. Voltar a lembrar implica um esforço deliberado da mente; é uma espécie de escavação ou de busca voluntária entre os conteúdos da alma (Rossi, 2010). Nesta demanda do passado imagens e lugares reforçaram a ideia de pertencimento, que tem a função de fortalecer e mesmo forjar a memória. A criação de locais especiais fortaleceram as crenças religiosas; regiões e cidades sagradas tornaram-se espaços visíveis de algo espiritual. A Terra Santa, especialmente a cidade de Jerusalém é um destes espaços sublimes, local fundamental para a identidade cristã. Em seus escritos sobre memória coletiva Maurice Halbawachs enfatizou as relações entre espaço e memória, destacando sua importância no imaginário religioso: "As religiões estão solidamente instaladas sobre o solo, não apenas porque esta é uma condição que se impõe a todos os homens e todos os grupos, mas um grupo de fiéis é levado a distribuir entre as diversas partes do espaço o maior número de ideias e imagens que defende" (2003, p. 170). O espaço físico, mesmo que representativo, não dá conta da totalidade de signos necessários à perpetuação da memória. Para tanto é preciso incorporar um cenário mais intenso, dramático que consiga reunir os elementos necessários a uma lembrança singular.

No cristianismo os últimos dias e horas sofridos pelo Messias na terra, antes de sua crucificação, são especialmente revividos com intensidade. Locais como o Cenáculo, Getsêmani (no Monte das Oliveiras) e a Via Dolorosa tornaram-se gradativamente pontos cruciais da geografia sagrada. No local do horto foi construída a Igreja da Agonia (Igreja de todas as Nações), e mais recentemente a capela franciscana Dominus Flevit, em forma de lágrima ${ }^{14}$. Conforme o Evangelho de São Lucas (19: 41-

13 Fonte: https://br.pinterest.com/jacquelinevigri/

14 Inaugurada em 1955. 
44), ali do alto Jesus teria lamentado sobre o destino de Jerusalém: E, como estivesse perto, viu a cidade e chorou sobre ela, dizendo: Ah! Se neste dia também tu conhecesses a mensagem de paz! Agora, porém, isso está escondido a teus olhos. Pois dias virão sobre ti, e os teus inimigos te cercarão com trincheiras, te rodearão e te apertarão por todos os lados. Estes lugares simbólicos foram santificados pela tradição, e são visitados pelos peregrinos desde o século IV, demonstrando a força da narrativa bíblica, que deu sustentação a estas demarcações.

Figura 4: Dominus Flevit (Jerusalém) ${ }^{15}$

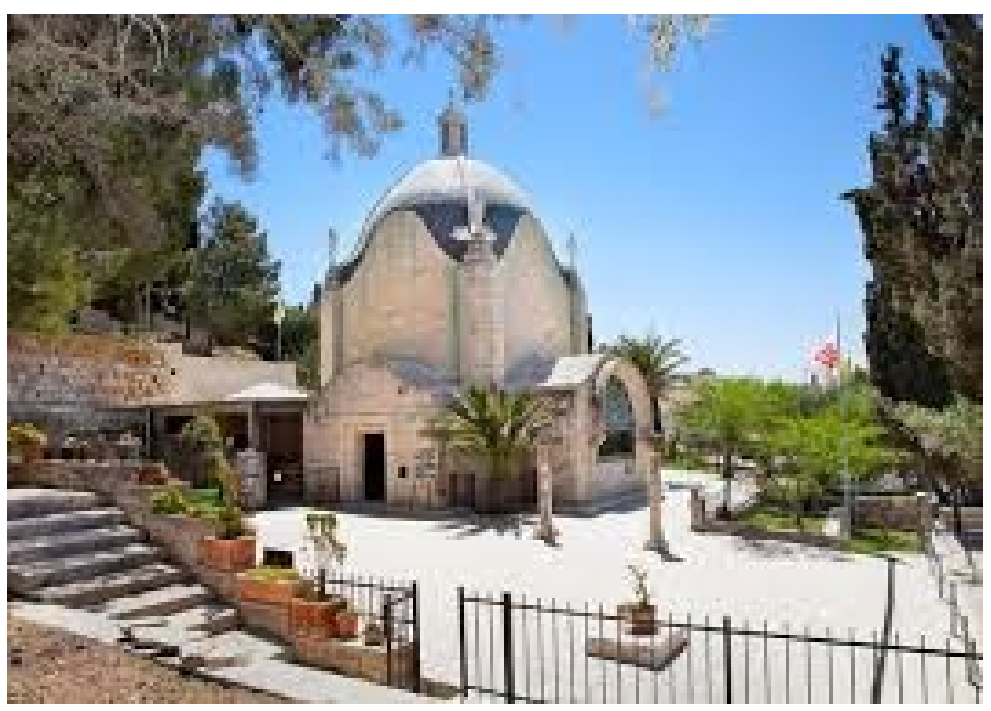

Estes pontos de referência no solo na Terra Santa, independente de sua localização arbitrária e nem sempre precisa, constituíram-se em elos entre passado/presente entre o material/espiritual. Revelam a consagração da memória coletiva sobre uma região e sua perpetuação enquanto modelo em outros espaços. As reações emotivas intensas presentes na Semana Santa reproduzem a agonia de Jesus, e conforme Mattoso (2013, p. 9), representam a tentativa humana de neutralizar, captar ou dominar as misteriosas forças sagradas que desafiam ou perturbam o ser humano. O contexto imaginário em que se inserem vai evoluindo e proliferando segundo mecanismos complexos que se refazem sem cessar.

\section{Referências}

BÍBLIA DE JERUSALÉM. SP: Paulus. 2013 (9ª impressão)

CORDEIRO, Veridiana Domingos. Por uma Sociologia da Memória: Análise e Interpretação da Teoria da Memória Coletiva de Maurice Halbwachs. Dissertação de Mestrado do Programa de Pós- Graduação em Sociologia da Faculdade de Filosofia, Letras e Ciências Humanas da Universidade de São Paulo. SP, 2015.

DURKHEIM, Émile. As Formas Elementares da Vida Religiosa [1912]. SP: Ed. Martins Fontes, 2003.

${ }^{15}$ Fonte: https://www.viator.com/Jerusalem-attractions/Dominus-Flevit/d921-a18545 
Egéria. Viagem do Ocidente à Terra Santa, no Séc. IV (Itinerarium ad loca sancta). Edição de Alexandra B. Mariano e Aires do Nascimento. Lisboa: Colibri, 2009 (2a tiragem).

ELIADE, Mircea. O Sagrado e o Profano. SP: Martins Fontes, 1992.

FONTES FRANCISCANAS ( I ) São Francisco de Assis. Escritos. Biografias. Documentos. Braga: Editorial Franciscana, 2005.

FRANÇA, Susani S. L; NASCIMENTO, Renata Cristina de S; LIMA, Marcelo Pereira. Peregrinos e Peregrinação na Idade Média. Petrópolis: Editora Vozes, 2017.

HALBWACHS, Maurice. A Memória Coletiva. São Paulo: Centauro, 2003.

HALBWACHS, Maurice. La topographie légendaire des évangiles en Terre Sainte: étude de mémoire collective. Paris: Universitaires de France, 1941.

MATTOSO, José. Poderes Invisíveis. O Imaginário Medieval. Lisboa: Temas \& Debates, 2013.

NASCIMENTO, Renata Cristina de S. Nascimento. Viagens Reais e Imaginadas: Dois Olhares Sobre a Terra Santa. In Revista de História Comparada. Rio de Janeiro, v. 12, n. 1, p. 08-20, 2018.

NASCIMENTO, Renata Cristina de S. \& SILVA, Paulo Duarte. Ensaios de História Medieval. Temas que se Renovam. Curitiba: Editora CRV, 2019.

NASCIMENTO, Renata Cristina de Sousa. A Cristianização do Espaço: O Protagonismo da Vera Cruz em Marmelar. In Revista Tempos Históricos, Volume 20. Unioeste: $2^{\circ}$ Semestre de 2016. p. 133-146. Disponível em: http://erevista.unioeste.br/index.php/temposhistoricos/article/view/15737/10691.

PELIKAN, J. A imagem de Jesus ao longo dos séculos. São Paulo: Cosac \& Naif Edições, 2000.

PERRIN, Michel-Yves. Cristianização do espaço e cristianização do tempo. In: CORBIN, Alain (dir.). História do Cristianismo. Lisboa: Presença, 2008, p. 79- 82.

ROSSI, Paolo. O Passado, A Memória, O Esquecimento. Seis ensaios da história das ideias. SP: UNESP, 2010.

SCHMITT, Jean-Claude. O corpo, os ritos, os sonhos, o tempo. Ensaios de antropologia medieval. Petrópolis: Editora Vozes, 2014.

SILVEIRA, PX. Frei Confaloni: Via-Sacra. Goiânia: Editora Kelps, 2019.

TATSCH, Flávia Galli. As Transferências Artísticas na Europa Gótica. In: NASCIMENTO, Renata Cristina de S. \& SILVA, Paulo Duarte. Ensaios de História Medieval. Temas que se Renovam. Curitiba: Editora CRV, 2019. P. 107-123

VIGÁRIO, Jacqueline Siqueira. Diante da Sacralidade Humana: Produção e Apropriações do Moderno em Nazareno Confaloni (1950-1977). Tese de Doutorado apresentada ao Programa de Pós-Graduação em História da Faculdade de História da Universidade Federal de Goiás. Goiânia: 2017. 


\section{Notas de autoria}

Renata Cristina de Sousa Nascimento é doutora em História pela Universidade Federal do Paraná (UFPR). Participante do Núcleo de Estudos Mediterrânicos (NEMED). Professora associada III na Universidade Federal de Goiás (UFG), na Universidade Estadual de Goiás (UEG) e no Programa de Pós-Graduação em História da Pontifícia Universidade Católica de Goiás (PUC-Go). Realizou estágio de pesquisa na Universidade de Oviedo (janeiro-2019). Realizou estágios de pós-doutorado na Universidade do Porto (dez./2015-2016) e na Universidade Federal do Paraná (2012). Coordenadora do Grupo de Estudos Ibéricos/ CNPq. E-mail: renatacristinanasc@gmail.com.

Como citar esse artigo de acordo com as normas da revista

NASCIMENTO, Renata Cristina de Sousa. A memória em trânsito: uma leitura da Via Sacra enquanto construção coletiva. Sæculum - Revista de História, v. 24, n 41, p. 2434, 2019.

\section{Contribuição de autoria}

Não se aplica.

Consentimento de uso de imagem

Não se aplica.

\section{Aprovação de comitê de ética em pesquisa}

Não se aplica.

\section{Licença de uso}

Este artigo está licenciado sob a Licença Creative Commons CC-BY. Com essa licença você pode compartilhar, adaptar, criar para qualquer fim, desde que atribua a autoria da obra.

\section{Histórico}

Recebido em 31/07/2019.

Aprovado em 16/09/2019. 